자동차 미세먼지 배출량 산정의 타당성 분석

\author{
이임학 · 김진식* $\cdot$ 이승재** $\cdot$ 김신도*, ${ }^{*}$ \\ 서울시립대학교 도시과학연구원, *서울시립대학교 환경공학과, **서울시립대학교 교통공학과
}

(2014년 3월 3일 접수, 2014년 3월 21일 심사, 2014년 3월 25일 채택)

\title{
Validity Analysis of the Fine Particle Emission Calculating by Cars
}

\author{
Im Hack Lee, Jin Sik Kim*, Seungjae Lee**, and Shin Do Kim*,† \\ Institute of Urban Science, University of Seoul 13 Siripdaegil, Dongdaemun-Gu, Seoul 130-743, Korea \\ *Department of Environmental Engineering, The University of Seoul 13 Siripdaegil, Dongdaemun-Gu, Seoul 130-743, Korea \\ **Dept. of Transportation Engineering, University of Seoul 13 Siripdaegil, Dongdaemun-Gu, Seoul 130-743, Korea
}

(Received March 3, 2014; Revised March 21, 2014; Accepted March 25, 2014)

\begin{abstract}
본 연구에서는 도시대기 중 문제시 되는 미세먼지 배출원의 주범으로 추정되는 유류를 사용하는 도로배출원(자동차) 의 배출량 산정을 위한 배출계수 및 활동도 적용의 타당성과 미세먼지 제어를 위한 법제도 시행의 타당성에 대하여 분석하고 고찰하는 것을 연구의 목적으로 하였다. 실제 교통량에 근거하여 작성한 본 연구의 자동차 배출량 공간분석 결과와 기존 방법과의 차이가 나타났는데, 대기 미세먼지 농도를 알아보기 위한 대기분산모델링을 수행할 때 현실적이 지 않은 배출량을 입력할 경우, 농도분포 결과의 심각한 왜곡을 초래할 수 있기 때문에 자동차 배출 미세먼지 공간분 석은 실제 교통량에 근거하여 작성해야 할 것이다. 국립환경과학원방법(2010)에 사용된 자동차 미세먼지 배출계수는 주로 2003 2007년식의 자동차를 대상으로 하였기 때문에 DPF 장착 등의 효과를 반영할 수 없었고, 서울 인근 도로 노선별 자동차 미세먼지 배출량 산정결과 국립환경과학원방법과 본 연구방법의 결과가 상이하게 나타났는데, 승용차 배출량 중 휘발유차 배출량이 디젤차량 배출량과 대등하게 산정되었기 때문에, 현실에 맞는 디젤 및 휘발유 자동차 미세먼지 배출계수 개발이 필요하다.
\end{abstract}

\begin{abstract}
In this study, the purposes are investigating and analyzing car emission factors for estimating road emissions and the legal framework for the control of particulate matters. At the result, when input emission data are not realistic, the modeling output concentration distributions can lead to a serious distortion of the results. So, the spatial analysis of the dust emission vehicles have to be based on the actual traffic volumes. Because dust emission factors used in the car by National Institute of Environmental Research Method (2010) are mainly targeted for 2003-2007 cars these could not reflect the effect of DPF and the dust emission of gasoline passenger car. So, the real dust emission factors of diesel and gasoline cars need to be developed.
\end{abstract}

Keywords: validity PM road emission factor

\section{1. 서 론}

우리나라는 지금까지 미세먼지 관리와 관련하여 $\mathrm{CNG}$ 버스보급, $\mathrm{LPG}$ 택시, 경유차 배출허용기준 강화, 청정연료 사용확대, 제 1 차 수 도권 대기개선 특별대책 등을 실시해왔으나, 최근 미세먼지의 농도가 환경기준을 초과하는 사례가 자주 발생하고 있는 것과 관련하여 2013 년 12월에 관계부처와 합동으로 예경보, 국제협력, 저감대책 등을 골 자로 하는 미세먼지 종합대책을 발표하였다.

Lee 등[1]은 우리나라 국립환경 과학원에서 사용하던 자동차오염원 공간분석 방법에 의한 도로별 교통량 데이터의 산출방법은, 차량 연

† Corresponding Author: The University of Seoul, Department of Environmental Engineering, 13 Siripdaegil, Dongdaemun-Gu, Seoul 130-743, Korea

Tel: +82-2-6490-2860 e-mail: sdkim@uos.ac.kr

pISSN: 1225-0112@2014 The Korean Society of Industrial and Engineering Chemistry. All rights reserved.
고 지자체의 자동차 등록사업소에서 매년 실시하는 자동차 정기검사 시, 차량마다 부착된 적산 거리계로부터 산출된 연간 이동거리를 차 종별로 평균하여 시도별로 구분된 데이터를 사용한 것이기 때문에 왜 곡의 소지가 있을 수 있음을 지적하였다. 그리고 도로별 교통량 고려 가 가능하여 자동차 오염물질 배출량의 공간분석이 용이하며, “지속 가능한 교통물류발전법” 등에 의하여 수행하고자 하는 지자체별 녹색 교통 정책 등을 위한 실제적인 배출량 인벤토리 $\mathrm{DB}$ 수립 등이 용이할 수 있음을 보고하였다.

Lee 등[2]은 기존의 국내오염원 파악 연구에서는 분류되지 않았던 오염원들을 확인하였는데, 차량으로 인한 미세먼지 오염원에서 디젤 자동차와 가솔린자동차 오염원 이외에도 버스 오염원을 분리하였다. 이 결과는 도시대기의 인위적인 먼지 오염원 중 대표적 오염원인 차 량오염원을 관리할 때, 합리적으로 대기질 관리방안을 마련할 수 있 는 자료를 제공할 수 있다고 판단되었다.

기존에 우리나라에서는 공식적으로 가솔린 엔진에서는 미세먼지가 


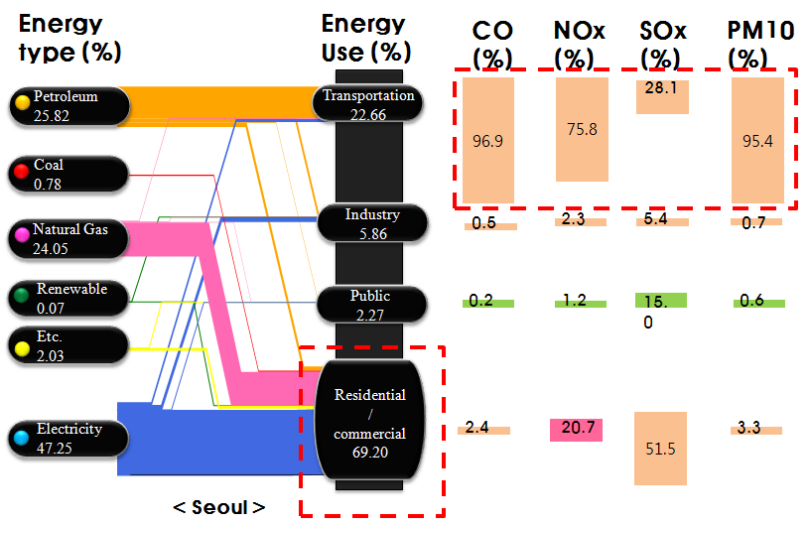

Figure 1. Urban energy usages and emissions of pollutants.
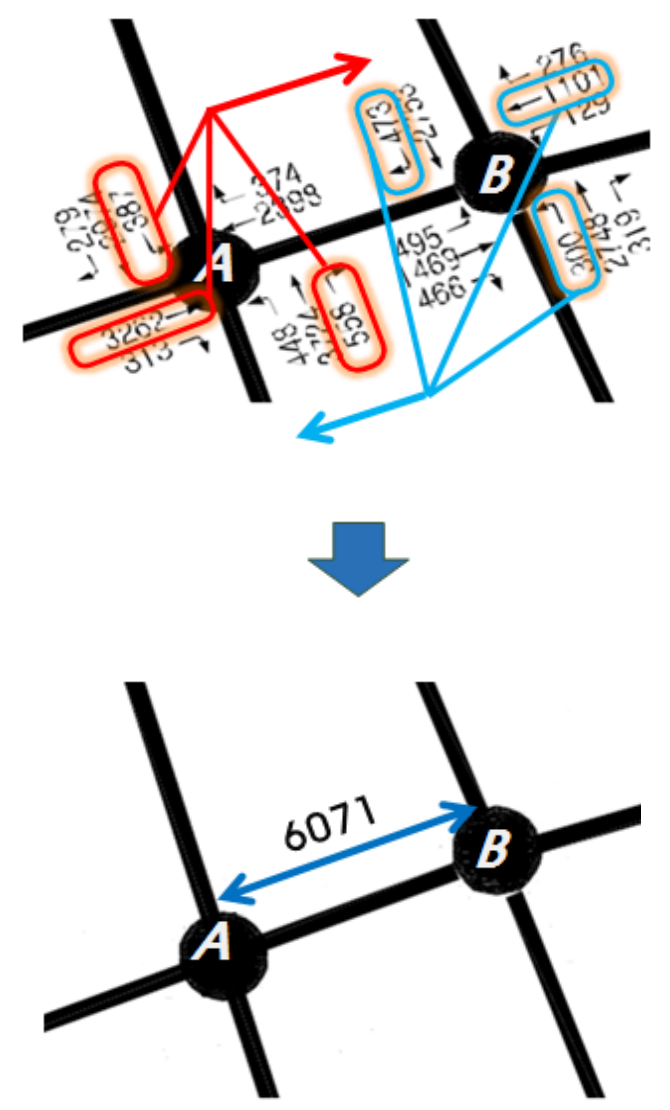

Figure 2. Traffic calculating method.

발생하지 않는 것으로 보고하였대[3,4]. 그러나 Paul 등[5]은 가솔린 엔진 에서도 미세먼지가 배출되었음을 보고하였고, 여기서 더 나아가 Huang 등[6]은 가솔린 자동차의 미세먼지 배출계수를 보고하기도 하였다. 경유 자동차에 대한 배출계수도 국립환경과학원이 2010년에 보고한 국가대기 오염물질배출량 산정방법편림[3]에 의하면 2007년 이전의 배출계수를 사 용하고 있어 2008년 이후 적용된 Diesel Particulate Filter 등을 고려하지 못하고 있었다. 국내 법규는 대기환경보전법 시행규칙 별표로서 제작차 미세먼지 배출허용기준을 나타내고 있었는데, 가솔린 자동차는 GDI (직 분사)엔진에 대해서만 2014년 1월부터 적용하기 시작하였고, 경유자동차 는 2009년부터 DPF를 고려한 배출허용기준을 적용한 것으로 판단되었다.
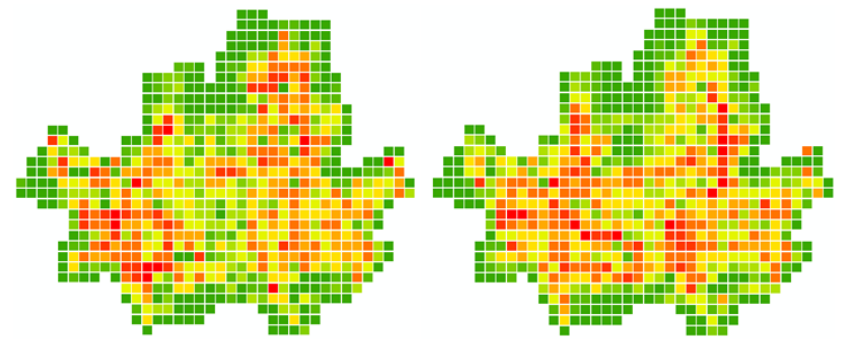

Figure 3. Spatial differences of car particulate matter emissions in Seoul by adapting traffic activities.

Figure 1은 서울에서의 에너지사용량과 그에 따른 대기오염물질 배출량 의 그림을 나타낸 것이다. 에너지 사용량은 지역에너지통계연보에 기초했 으며, 배출량은 국립환경과학원의 CAPSS 자료를 활용하였다. 에너지 사용 분야를 수송, 선업, 공공, 가정 및 상업 등 4 개 분야로 나누었을 때, 수송분 야의 에너지 사용 기여도는 $22.66 \%$ 이었으나, 대기오염물질의 배출 기여도 는 황산화물을 제외하면 대부분을 차지하는 것으로 나타났는데, 특히 미세 먼지의 경우, 기여율이 $95.4 \%$ 를 나타내어 도시에서의 미세먼지 배출량은 유류 사용에 의한 수송부분의 기여율이 대부분을 차지한다고 말할 수 있다. 따라서, 본 연구에서는 도시대기 중 문제시 되는 미세먼지 배출원의 주 범으로 추정되는 유류를 사용하는 도로배출원(자동차)의 배출량 산정을 위 한 배출계수 및 활동도 적용의 타당성과 미세먼지 제어를 위한 법제도 시 행의 타당성에 대하여 분석하고 고찰하는 것을 연구의 목적으로 하였다.

\section{2. 실 험}

기존의 국가배출량은 국립환경과학원의 대기오염물질산정방법편람 산정방법에 따른 CAPSS (Clean Air Policy Support System) 데이터를 이용하였으며, 본 연구에서는 다음의 방법을 사용하여 서울시 도로의 미세먼지 배출량을 산정하였다.

서울특별시교통정보센터(http://topis.seoul.go.kr)에서는 서울지방경 찰청 종합교통정보센터와 연계하여, 서울시 주요 간선도로의 교통량 조사자료를 확보하고 있기 때문에, 본 연구에서는 이를 바탕으로 서울 시 내의 도로를 통행하는 자동차의 교통량 자료를 바탕으로 한 구간별 활동도를 적용하였다.

조사된 자료는 차종의 종류를 소형과 대형으로 구분하고, Figure 2와 같이 $\mathrm{A}$ 번 방향에서 $\mathrm{B}$ 번 방향으로 진행되는 차량을 합산하고, $\mathrm{B}$ 번 교차 로에서 $\mathrm{A}$ 번 교차로로 진행하는 차량을 합산하여 한 구간의 교통량을 산정한 후 GIS 데이터 형식의 자료를 구축하여 배출량을 산정하였다. 측정된 교통량으로부터 자동차 주행거리를 산정하고, 차종별 혼입 률과 시간보정계수를 적용하여 연간 차종별 주행거리(V.K.T)를 산정 한 후, GIS (Geographic Informaion System)의 추출기능을 이용하여 격자별 배출량을 산정하였다.

배출계수 적용에 대한 타당성 분석은 국립환경과학원의 자동차 미 세먼지 배출계수를 적용한 결과와 본 연구에서 제안하는 결과를 비교 분석하는 방법으로 수행하였다. 


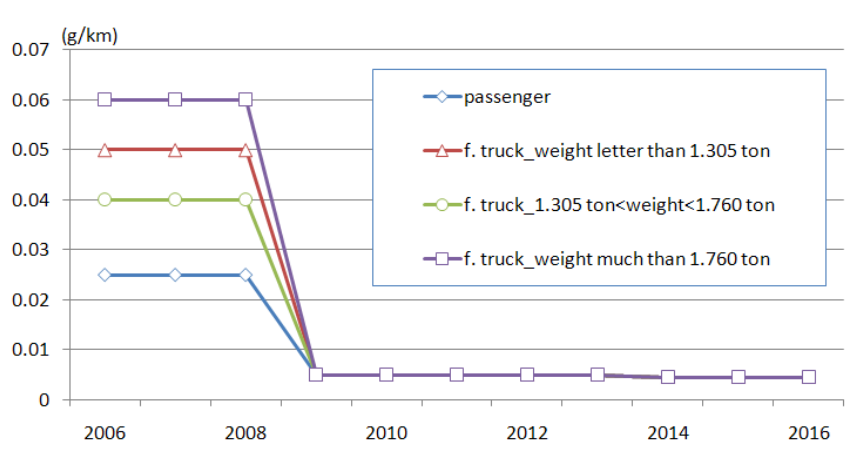

Figure 4. Emission guidelines of particulate matters for domestic diesel cars.

Table 1. Diesel Car Emission Factors of National Institute of Environmental Research

\begin{tabular}{ccc}
\hline Item & Velocity & Equation \\
\hline $\begin{array}{c}\text { passenger car below } \\
16 \text { people taking }\end{array}$ & $\begin{array}{c}\text { faster than } \\
65 \mathrm{~km} / \mathrm{h}\end{array}$ & $\begin{array}{c}\mathrm{Y}=-0.00001 \mathrm{~V}^{2}+ \\
0.0029 \mathrm{~V}-0.1455\end{array}$ \\
bus & $\begin{array}{c}\text { faster than } \\
65 \mathrm{~km} / \mathrm{h}\end{array}$ & $1.1507 \mathrm{~V}^{-0.4804}$ \\
& $\begin{array}{c}\text { faster than } \\
65 \mathrm{~km} / \mathrm{h}\end{array}$ & $0.1759 \mathrm{~V}^{-0.5357}$ \\
small freight truck & faster than \\
& $65 \mathrm{~km} / \mathrm{h}$ & $0.2979 \mathrm{~V}^{-0.4008}$ \\
medium freight truck & faster than \\
& $65 \mathrm{~km} / \mathrm{h}$ & $2.6847 \mathrm{~V}^{-0.6112}$ \\
large freight truck &
\end{tabular}

unit : $(g / k m)$

\section{3. 결과 및 고찰}

본 연구에서 산정한 Bottom-up 방식과 기존 국립환경과학원의 CAPSS에서 제공하는 Top-down 방식에 의한 격자별 도로수송부문 PM10 배출량을 비교하였다.

본 연구의 실제 교통량 방식의 배출량에 비해 기존의 인벤토리 방 식은 차량 주소지를 기준으로하기 때문에, 공간적 왜곡이 나타나는 것을 알 수 있었다.

즉 기존방식에서는 강서구 지역의 서부트럭 터미널 등의 입지에 의 하여 배출량이 많은 것으로 나타났으나, 본 연구방식에 의하면 교통 량이 적어 배출량이 상대적으로 낮게 나타났다. 기존 방식에 의하면 주거지인 강북구, 도봉구 지역의 자가용 등록대수가 많아 배출량이 높은 것으로 나타났으나, 실제 교통량에 의하면 주거지 보다는 동부 간선, 강변북로, 내부순환, 강남대로 등 지역의 배출량이 높게 나타남 을 보였다.

특히 이러한 현상은 향후 대기 미세먼지 농도를 알아보기 위한 대기분 산모델링 수행 시 현실적이지 않은 배출량 입력 시, 농도분포 결과의 심 각한 왜곡을 초래할 수 있기 때문에 매우 중요한 사안이라고 판단된다.

앞선 연구결과에서는 자동차의 배출량을 산정하는 방법에 따라, 공 간적인 분포가 달라짐을 보였다. 그런데, 우리나라에서 일반적으로 사

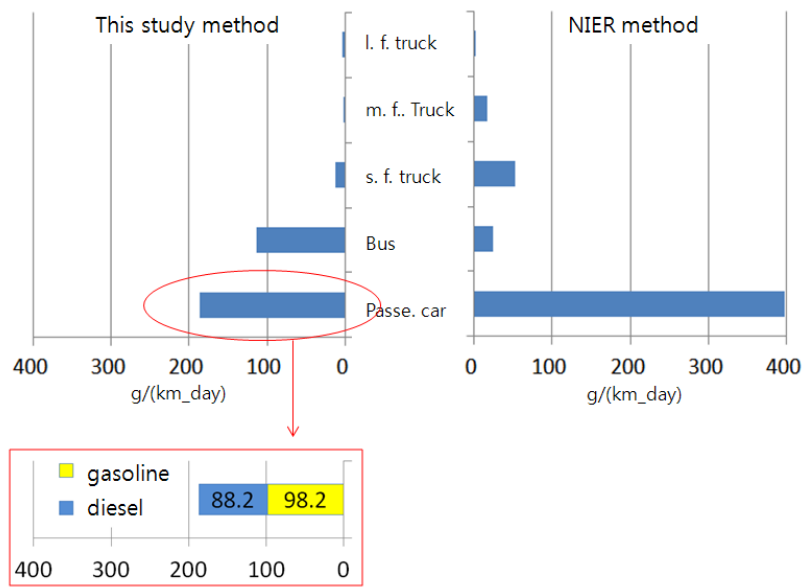

Figure 5. PM-10 emissions of on-road cars (Yongin-Seoul).
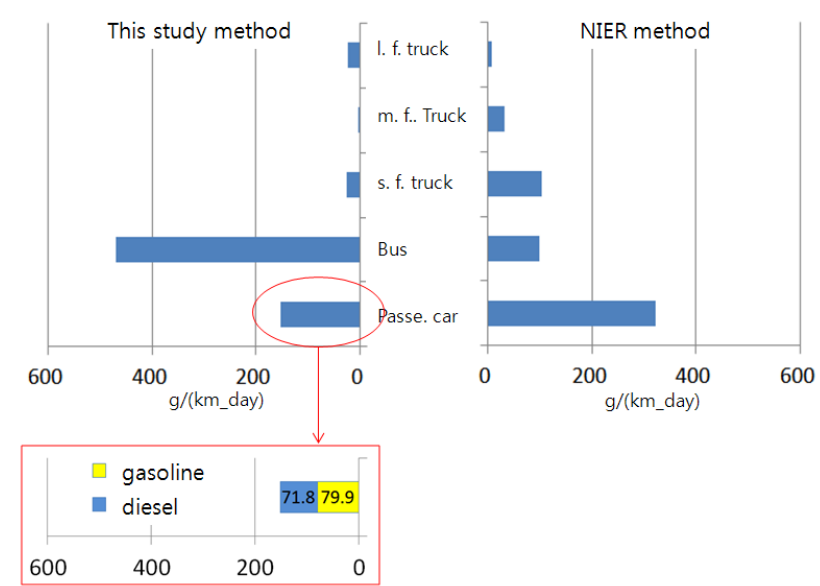

Figure 6. PM-10 emissions of on-road cars (Munsan-Seoul).

용되는 자동차 미세먼지 배출계수를 어떻게 적용하느냐에 따라서도 배출량의 변화가 있을 수 있다. 따라서, 본 논문의 고찰부분에서는 자 동차 배출량 산정에 사용되는 배출계수 적용의 타당성을 분석하였다.

우선 법규 내용을 분석하였다. 2013년까지 우리나라 대기환경보전 법 상에서는 자동차 미세먼지 배출량은 경유차에서만 배출되는 것으 로 규정하여 미세먼지에 대해서는 경유차의 배출허용기준만이 존재하 였다. Figure 4는 2006년 이후 연도별 우리나라 대기환경보전법 상의 중형 이하 경유 제작차의 배출허용기준을 나타낸 그래프이다. 2008년 까지는 배출계수가 차종이 커질수록 크게 규정되고 있었으나, 2009년 부터는 차종에 상관없이 $0.005 \mathrm{~g} / \mathrm{km}$ 로서 낮게 유지되고 있었으나 2014년부터는 $0.0045 \mathrm{~g} / \mathrm{km}$ 이하로 강화되고 있었다. 이는 2009년부터 경유차 전반에 적용되는 DPF (Diesel Particulate Filter)를 고려한 조치 로 볼 수 있다.

휘발유차 먼지 배출허용기준에 대해서는 2014년부터 제작차 배출 허용기준(대기환경보전법 시행규칙 별표 17)과 저공해차배출허용기 준(수도권 대기환경개선에 관한 특별법 시행규칙 별표2)에 모두 GDI (직분사) 엔진에 대한 배출허용기준만이 존재하고 있었다.

다음으로 자동차의 미세먼지 배출계수를 분석하였다. Table 1은 우 리나라 국립환경과학원에서 2010년에 제안한 경유자동차의 미세먼지 배출계수이다. 차속과 차종을 고려하여 제안하였는데, 방정식으로 되 어 있어 배출허용기준과 직접비교가 되지 않아, Figures 5-7에 배출량 


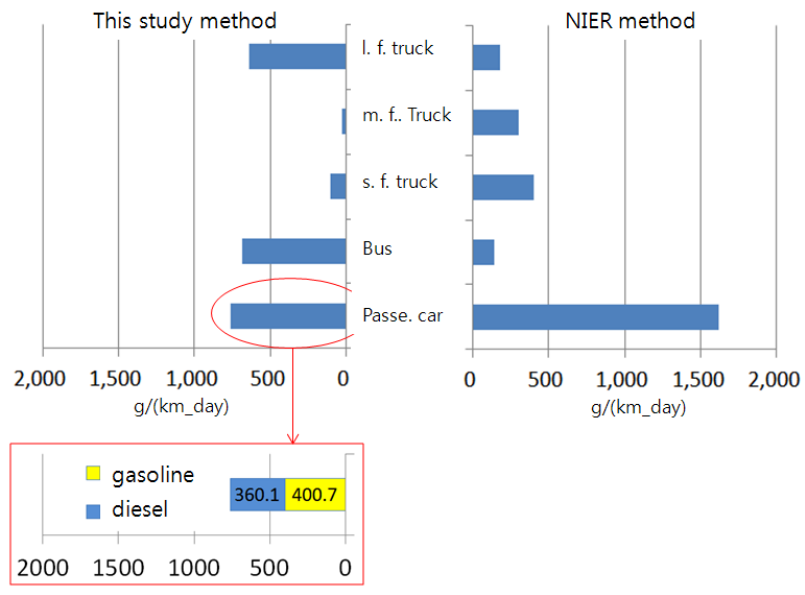

Figure 7. PM-10 emissions of on-road cars (a beltway around Seoul).

Table 2. Fine Particle Emission Factors by Car Types (China: 2012)

\begin{tabular}{ccc}
\hline car type & $\begin{array}{c}\text { fine particle } \\
\text { emission factors } \\
(\mathrm{g} / \mathrm{km})\end{array}$ & notes \\
\hline $\begin{array}{c}\text { large diesel bus } \\
(2010 \text { type })\end{array}$ & 0.6700 & $\begin{array}{c}7,100 \mathrm{cc} \\
\mathrm{SCR}\end{array}$ \\
small diesel passenger car \\
$\begin{array}{c}\text { (2010 type) } \\
\text { small gasoline passenger car } \\
(2011 \text { type })\end{array}$ & 0.1700 & $\begin{array}{c}1,900 \mathrm{cc} \\
\text { diesel oxidation } \\
\text { catalyst }\end{array}$ \\
& 0.0047 & $\begin{array}{c}1,800 \mathrm{cc} \\
\text { three-way catalyst }\end{array}$ \\
\hline
\end{tabular}

산정결과를 그래프로 나타낸 결과 현재 대기환경보전법 상의 배출허 용기준을 반영하고 있지 못하고 있다는 것을 알 수 있었다. 이에 대해 서는 향후 추가연구를 통한 보완이 필요할 것이다.

세 번째 타당성 분석의 주제는 '과연 미세먼지는 디젤 자동차에서 만 배출되는가'이다. 대기환경보전법 상에서와 같이 국립환경과학원 에서 발표한 자동차 미세먼지 배출계수를 나타내는 Table 1에서도 현 재까지 우리나라에서 자동차로부터 배출되는 미세먼지는 경유차에서 만 배출된다고 설정하였는데, 최근 연구에 의하면 휘발유 자동차 등 에서도 배출되는 것으로 보고되고 있다.

Huang 등[6]이 보고했던 중국의 차종별 미세먼지 배출계수를 Table 2에 나타내었다. 표에서 보면 2011년형 $1,800 \mathrm{cc}$ 급의 삼원촉매장치를 보유한 휘발유 승용차도 $0.0047 \mathrm{~g} / \mathrm{km}$ 의 미세먼지를 배출한다고 보고 하고 있다.

이는 우리나라의 대기환경보전법에서 2014년 이후부터 규정하고 있는 $\mathrm{GDI}($ 직분사) 엔진의 미세먼지 배출허용기준인 $0.004 \mathrm{~g} / \mathrm{km}$ 와 중 형 이하 디젤자동차의 미세먼지 배출허용기준인 $0.0045 \mathrm{~g} / \mathrm{km}$ 를 상회 하는 수치로서, 만약 일반 휘발유 승용차에서 Huang의 보고[6]와 같 이 미세먼지가 배출된다면, 우리나라에서 운행하고 있는 일반휘발유 승용차에 대한 미세먼지 배출에 대한 측정도 공식적으로 이루어져야 한다고 사료되었다.

위 자료를 근거로 하여, DPF 등을 고려한 디젤 엔진의 새로운 배출 계수를 반영하고, 휘발유 자동차의 미세먼지 배출이 이루진다고 가정
Table 3. Road Traffic Near by Seoul (Cars/Day: 2012)

\begin{tabular}{cccccc}
\hline section & $\begin{array}{c}\text { passenger } \\
\text { car }\end{array}$ & bus & $\begin{array}{c}\text { small } \\
\text { freight } \\
\text { truck }\end{array}$ & $\begin{array}{c}\text { medium } \\
\text { freight } \\
\text { truck }\end{array}$ & $\begin{array}{c}\text { large } \\
\text { freight } \\
\text { truck }\end{array}$ \\
\hline $\begin{array}{c}\text { Yong in - } \\
\text { Seoul }\end{array}$ & 48,742 & 170 & 3,092 & 319 & 5 \\
$\begin{array}{c}\text { Mun san - } \\
\text { Seoul }\end{array}$ & 39,656 & 702 & 6,096 & 612 & 36 \\
$\begin{array}{c}\text { beltway } \\
\text { around Seoul }\end{array}$ & 198,949 & 1,020 & 23,941 & 5,867 & 955 \\
\hline
\end{tabular}

Table 4. Fuel Ratios by Car Types in Seoul (Cars, \%)

\begin{tabular}{cccc}
\hline item & gasoline & diesel & LPG \\
\hline \multirow{2}{*}{ passenger car } & 706,257 & 493,518 & 296,673 \\
& $(47.2)$ & $(33.0)$ & $(19.8)$ \\
& 508 & 103,491 & 48,732 \\
van & $(0.3)$ & $(67.8)$ & $(31.9)$ \\
& & & \\
freight truck & $(0.3)$ & $(85.0)$ & $(14.7)$ \\
& & & \\
special car & 15 & 4,559 & 46 \\
& $(0.3)$ & $(98.7)$ & $(1.0)$ \\
\hline
\end{tabular}

하였을 때, 기존의 배출량과 어느 정도 차이가 나는지에 대하여 분석 하였다.

지금까지 분석한 배출계수를 실제 서울 인근 도로에 적용하기 위하 여 2012년 도로교통량 통계연보 자료[7]의 용인-서울, 문산-서울, 서울 외곽순환도로 등 3 개 노선별 교통량을 분석하였다. 용인-서울 구간은 버스나 화물차에 비하여 승용차의 비율이 상당히 높은 경우이고, 버 스의 비율이 상대적으로 높았으며, 서울외곽순환도로는 대형화물의 비율이 다른 노선에 비하여 높은 경우이다.

그런데, 미세먼지 배출계수를 교통량에 적용시키려면, 차종별 카테 고리가 서로 맞지 않는 경우가 발생하였다.

따라서, 본 연구에서는 통계청이 발표한 서울의 차종별, 유종별 등 록대수[8]에 근거하여 Table 3 과 Table 4 의 데이터를 생성한 후, 노선 별 배출량을 산정에 적용하였다.

Figures 5-7에 본 연구방법의 배출량산정 결과와 국립환경과학원[3] 에서 제시한 배출계수를 이용한 배출량 산정 결과를 비교하였다. 휘 발유 자동차와 버스는 Huang[6]의 배출계수를 적용하였고, 소형, 중형 화물트럭은 우리나라 대기환경보전법 상의 2009년부터의 배출허용기 준인 $0.005 \mathrm{~g} / \mathrm{km}$ 를 적용하였다.

용인-서울간 도로의 경우, 국립환경과학원 방법 결과는 승용차 배 출량이 절대적으로 높게 나타난데 비하여 본 연구방법의 결과에서는 버스 배출량이 승용차 배출량의 $61 \%$ 로 나타났다.

문산-서울 도로의 경우, 국립환경과학원 방법의 결과는 서울-용인 도로와 마찬가지로 승용차 배출량의 비중이 상대적으로 높게 나타났 는데, 본 연구방법의 결과에서는 타 노선에 비하여 버스 교통량의 비 율이 높았던 관계로 버스 배출량이 높게 나타났다. 서울외곽순환 도 로의 경우, 국립환경과학원 방법의 결과는 앞선 2 개 노선의 결과와 마 
Table 5. Fuel Ratios by Car types in Seoul Modified (cars, \%)

\begin{tabular}{ccccc}
\hline item & gasoline & diesel & LPG & sum \\
\hline passenger car + van & 42.9 & 36.2 & 20.9 & 100.0 \\
$\begin{array}{c}\text { freight truck }+ \text { special } \\
\text { car }\end{array}$ & 0.3 & 85.2 & 14.5 & 100.0 \\
\hline
\end{tabular}

찬가지로 승용차 배출량 비율이 절대적으로 높게 나타났는데, 본 연 구방법의 결과에서는 대형트럭의 비율이 타 노선에 비하여 상대적으 로 높았기 때문에 배출량 결과는 승용차, 버스, 대형화물의 비율이 대 등하게 나타났다.

위와 같은 결과는 국립환경과학원방법에 사용된 자동차 미세먼지 배출계수는 주로 2003 2007년식의 자동차를 대상으로 하여 DPF 장 착 등의 효과를 반영할 수 없었기 때문에 상대적으로 본 연구방법에 비하여 높게 산정되었다고 판단되었다.

버스와 대형화물 배출량의 차이가 나는 것은, 국립환경과학원의 방 법이 대형디젤엔진의 배출계수 실험은 엔진을 차량에 탑재하고 배출 계수 실험을 진행하지 않고 차체에서 엔진을 탈거 후 엔진 자체에 부 하를 주어 나오는 미세먼지 배출량을 산정하여 단위가 $\mathrm{g} / \mathrm{kw}$ 였기 때문 에, 본 연구에서 적용하고자 하는 배출계수 단위인 $\mathrm{g} / \mathrm{km}$ 로 적용하기 에는 한계가 있었다.

이 때문에 본 연구에서는 $\mathrm{g} / \mathrm{km}$ 단위인 중국 배출량을 적용하여 배 출량 산정 결과의 차이가 발생했던 것인데, 우리나라도 버스나 대형 화물의 엔진에 대해서 $\mathrm{g} / \mathrm{km}$ 단위로 실험을 하거나, $\mathrm{g} / \mathrm{kw}$ 를 $\mathrm{g} / \mathrm{km}$ 로 변 환하는 방법을 제안할 필요성이 있다고 판단되었다.

\section{4. 결 론}

도시대기 중 문제시 되는 미세먼지 배출원의 주범으로 추정되는 유 류를 사용하는 도로배출원(자동차)의 배출량 산정을 위한 배출계수 및 활동도 적용의 타당성과 미세먼지 제어를 위한 법제도 시행의 타 당성에 대하여 분석, 고찰한 결과는 다음과 같다.

대기 미세먼지 농도를 알아보기 위한 대기분산모델링 수행 시 현실 적이지 않은 배출량 입력 시, 농도분포 결과의 심각한 왜곡을 초래할 수 있기 때문에 자동차 배출 미세먼지 공간분석은 실제 교통량에 근 거하여 작성해야 할 것이다.

용인-서울간 도로, 문산-서울 도로, 서울외곽순환 도로의 경우, 국립 환경과학원 방법의 결과와 본 연구방법의 결과에서 차종별 배출량 비
율이 상이하게 나타났다. 이는 국립환경과학원방법에 사용된 자동차 미세먼지 배출계수는 주로 2003 2007년식의 자동차를 대상으로 하 였기 때문에 DPF 장착 등의 효과를 반영할 수 없었고, 서울 인근 도 로 노선별 자동차 미세먼지 배출량 산정결과 승용차 배출량 중 휘발 유차 배출량이 디젤차량 배출량과 대등하게 산정되었기 때문이라고 사료되므로, 현실에 맞는 디젤 및 휘발유 자동차 미세먼지 배출계수 개발이 필요할 것이다.

교통량에 근거하여 자동차 미세먼지 배출량을 산정하는 mobile 6 모델의 결과를 입력하여 대기분산모델인 Calpuff 모델을 수행하여, 도 시의 미세먼지 거동특성을 분석하는 연구를 수행되어야 할 것이다.

\section{감 사}

이 논문 또는 저서는 2012년 정부(교육과학기술부)의 재원으로 한국 연구재단의 지원을 받아 수행된 연구임(NRF-2012S1A5B8A03045234).

\section{참 고 문 헌.}

1. I. H. Lee, S. J. Lee, J. S. Park, and S. D. Kim, Area Wide Calculation of Traffic Induced $\mathrm{CO}_{2}$ Emission in Seoul, KSCE Civil Eng., 16, 450-456 (2012).

2. H. W. Lee, Tae Jung Lee, and Dong Sool Kim, Identifying Ambient PM2.5 Sources and Estimating their Contributions by Using PMF : Separation of Gasoline and Diesel Automobile Sources by Analyzing ECs and OCs, J. Korean Soc. Atmos. Environ., 25, $75-89$ (2009).

3. National Institute of Environmental Research(NIER), National Air Pollution Emission Calculation Method Manual( $\Pi)$, Report of National Institute of Environmental Research, Korea (2010).

4. National Institute of Environmental Research(NIER), National Air Pollutant Emission, http://airemiss.nier.go.kr/nape/statistics/airpollution/fuel/retrieve.jsp (2014).

5. B. Paul, A. Datta, A. Datta, and A. Saha, Optical characterization of nano-sized organic carbon particles emitted from a small gasoline engine, Particuology, 11, 249-255 (2013).

6. C. Huang, D. Lou, Z. Hua, Q. Feng, Y. Chen, C. Chen, P. Tan, and D. Yao, A PEMS study of the emissions of gaseous pollutants and ultrafine particles from gasoline and diesel-fueled vehicles, Atmospheric Environment, 77, 703-710 (2013).

7. Ministry of Land, Infrastructure and Transport, 2012 Statistical Yearbook of Traffic Volume (2013).

8. Statistics Korea, Present condition of vehicle registration, http://ww w.index.go.kr/egams/stts/jsp/potal/stts/PO_STTS_IdxMain.jsp?idx_cd $=1257 \& b b s=I N D X \_001 \& c l a s \_d i v=C \&$ rootKey $=1.48 .0$ (2012). 